\title{
Papers
}

\section{Predictors for the development of microalbuminuria and macroalbuminuria in patients with type 1 diabetes: inception cohort study}

Peter Hovind, Lise Tarnow, Peter Rossing, Berit Ruud Jensen, Malene Graae, Inge Torp, Christian Binder, Hans-Henrik Parving

\begin{abstract}
Objective To evaluate baseline predictors for the development of persistent microalbuminuria and macroalbuminuria prospectively in patients with type 1 diabetes.

Design Prospective observational study of an inception cohort. Setting Outpatient diabetic clinic in a tertiary referral centre, Gentofte, Denmark.

Participants 286 patients (216 adults) newly diagnosed with type 1 diabetes consecutively admitted to the clinic between 1 September 1979 and 31 August 1984.

Main outcome measures Persistent microalbuminuria and persistent macroalbuminuria.

Results During the median follow up of 18.0 years (range 1.0-21.5 years), total of 4706 patient years of follow up, 79 of 277 (29\%) patients developed persistent microalbuminuria. 27 of 79 progressed further to persistent macroalbuminuria. The cumulative incidence of persistent microalbuminuria and persistent macroalbuminuria was $33.6 \%$ (95\% confidence interval $27.2 \%$ to $40.0 \%)$ and $14.6 \%(8.9 \%$ to $20.3 \%)$, respectively. Significant predictors for the development of persistent microalbuminuria were a 10 -fold increase in urinary albumin excretion rate (relative risk $3.78,1.57$ to 9.13 ), being male (2.41, 1.43 to 4.06 ), a $10 \mathrm{~mm} \mathrm{Hg}$ increase in mean arterial blood pressure (1.38, 1.20 to 1.57$)$, a $1 \%$ increase in haemoglobin $\mathrm{A}_{\mathrm{lc}}(1.18,1.04$ to 1.32$)$, and a $1 \mathrm{~cm}$ increase in height $(0.96,0.95$ to 0.98$)$. 28 patients with microalbuminuria $(35 \%)$ regressed to normoalbuminuria either transiently $(\mathrm{n}=15)$ or permanently $(\mathrm{n}=13)$.

Conclusions Around one third of patients newly diagnosed with type 1 diabetes develop persistent microalbuminuria within the first 20 years of diabetes. Several potentially modifiable risk factors predict the development of persistent microalbuminaria and persistent macroalbuminuria.
\end{abstract}

\section{Introduction}

Persistent microalbuminuria (urinary albumin excretion rate between 30 and $300 \mathrm{mg} / 24 \mathrm{~h}$ ) is an established risk factor for the development of overt diabetic nephropathy (urinary albumin excretion rate $>300 \mathrm{mg} / 24 \mathrm{~h}$ ). ${ }^{1-3}$ Microalbuminuria may be regarded as an early marker of diabetic kidney disease, as renal structural lesions can be detected at this stage. ${ }^{4}$ Previous studies on risk factors for the development of microalbuminuria and diabetic nephropathy are based on prevalence cohorts, often with short term follow up, and include patients with varying

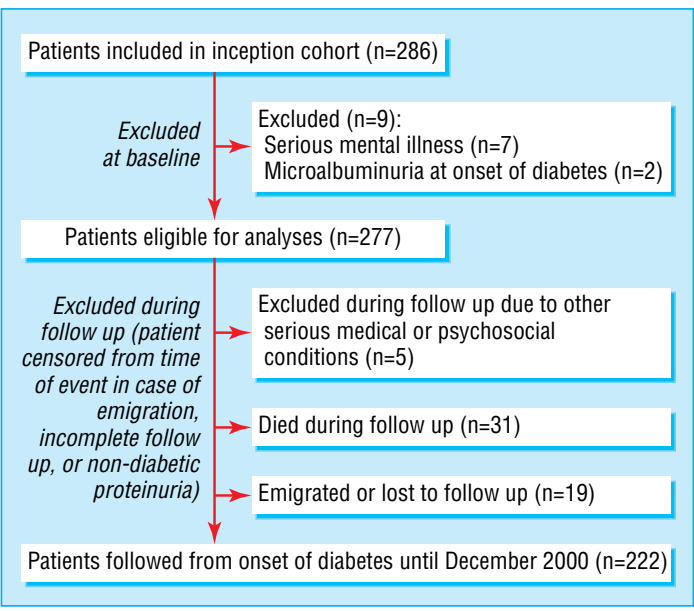

Fig 1 Study design

duration of diabetes, thus introducing potential selection and survivor bias. ${ }^{5-8}$ We analysed a large inception cohort of patients newly diagnosed with type 1 diabetes followed for a median of 18 years to evaluate baseline predictors for the development of persistent microalbuminuria and diabetic nephropathy. We also explored factors associated with regression of microalbuminuria to normoalbuminuria (urinary albumin excretion rate $<30$ $\mathrm{mg} / 24 \mathrm{~h})$.

\section{Methods}

Our study sample comprised all patients newly diagnosed with type 1 diabetes consecutively admitted to the Steno Diabetes Centre between 1 September 1979 and 31 August 1984. ${ }^{9}$ The inception cohort included 286 patients (fig 1). Nine patients were excluded; seven had serious mental illness and two had microalbuminuria at the onset of diabetes.

The patients attended the outpatient clinic every three or four months as part of routine follow up. They were treated by diabetologists and nurses according to previously described guidelines. ${ }^{9}$ They received no specific intervention. From 1 January 1980 , haemoglobin $A_{1 c}$ was measured at each visit. ${ }^{9}$

Urinary albumin excretion over 24 hours was measured in each patient at least once a year. ${ }^{9}$ Persistent microalbuminuria and persistent macroalbuminuria were defined as a urinary albumin excretion rate between 30 and $300 \mathrm{mg} / 24 \mathrm{~h}$ and $>300$ 
$\mathrm{mg} / 24 \mathrm{~h}$, respectively, in at least two of three consecutive samples, with an increase of at least 30\% above the baseline level. ${ }^{10}{ }^{11}$ Regression to normoalbuminuria from microalbuminuria was defined as a urinary albumin excretion rate less than $30 \mathrm{mg} / 24 \mathrm{~h}$ in two of three consecutive 24 hour urine collections and a decrease of at least 30\% from the microalbuminuria level, sustained for at least one year. Basal serum $\mathrm{C}$ peptide levels were measured by radioimmunoassay after an overnight fast. $^{12}$

Arterial blood pressure was measured at least once a year with a standard mercury sphygmomanometer while the patient was sitting after resting for 10 minutes. Patients were classified as smokers if they smoked more than one cigarette a day; smoking history was elicited by questionnaire. Retinopathy was assessed through dilated pupils and graded as absent, simplex, or proliferative. $^{9}$

\section{Statistical analysis}

Baseline data were from the first assessment six months after the onset of type 1 diabetes, after initial glycaemic stabilisation. Baseline data are expressed as means (standard deviations) or medians (interquartile ranges) and follow up data are expressed as means (standard errors of means) or geometric means (95\% confidence intervals). We compared groups by unpaired Student's $t$ test for normally distributed variables and by KruskalWallis test for non-normally distributed continuous variables. Frequencies were compared by $\chi^{2}$ test. We calculated the cumulative incidence of microalbuminuria and macroalbuminuria using a life table method based on follow up ending on 31 December 2000. A Cox proportional hazards regression model was used to evaluate the relative contributions of covariates to the risk of developing persistent microalbuminuria, correcting for duration of follow up. Variables included were sex, age, smoking status, arterial blood pressure, log urinary albumin excretion rate, haemoglobin $A_{1 c}$ concentration, height, weight, cholesterol concentration, and fasting plasma $\mathrm{C}$ peptide level. A stepwise backward selection was used. The rate of progression in urinary albumin excretion rate was determined by linear regression analysis of logarithmically transformed values. We considered a $\mathrm{P}$ value of 0.05 or less as significant. Analyses were performed with SPSS (version 12).

\section{Results}

We followed 277 patients newly diagnosed with type 1 diabetes for a median of 18.0 years (range 1.0-21.5 years) with a total of 4706 patient years of follow up. Overall, 79 patients developed persistent microalbuminuria (cumulative incidence 33.6\% (95\% confidence interval $27.2 \%$ to $40.0 \%$ ). Of these, 27 progressed to persistent macroalbuminuria ( $14.6 \%(8.9 \%$ to $20.3 \%$; fig 2$)$. The urinary albumin excretion rate remained less than $30 \mathrm{mg} / 24 \mathrm{~h}$ in 198 patients. Males predominated in the group that progressed to microalbuminuria (table 1). At baseline, urinary albumin excretion rate and systolic and diastolic blood pressure were significantly higher in patients who developed persistent microalbuminuria (table 1). Patients who developed microalbuminuria tended to be shorter than those remaining normoalbuminuric. The two groups were similar for age at onset of diabetes, body weight, haemoglobin $\mathrm{A}_{1 c}$ concentration, serum cholesterol and creatinine concentrations, and fasting plasma $\mathrm{C}$ peptide level. No patients had diabetic retinopathy at baseline.

During follow up, urinary albumin excretion showed a sustained increase in patients who developed microalbuminuria (table 2). Haemoglobin $A_{1 c}$ concentration was significantly higher in the group that developed microalbuminuria $(9.1 \% v$

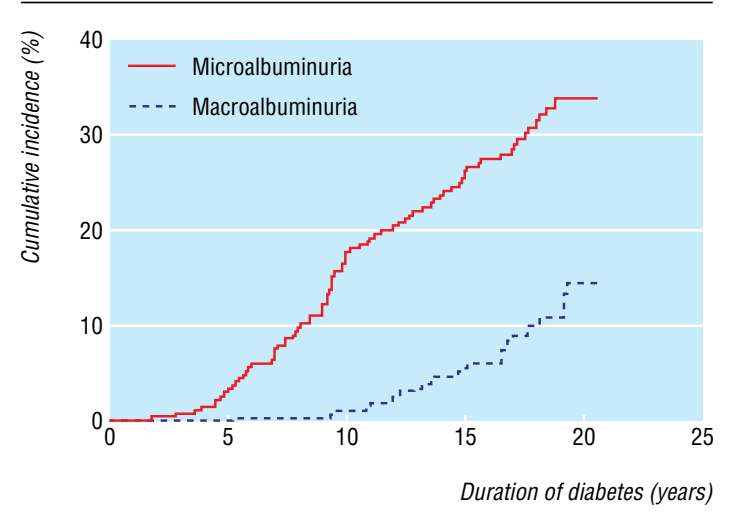

Fig 2 Cumulative incidence of persistent microalbuminuria (79 events) and macroalbuminuria (progressed from microalbuminuria, 27 events) in 277 patients newly diagnosed with type 1 diabetes from 1979 to 1984

$8.4 \%, \mathrm{P}<0.001)$. This group also had more patients who developed severe retinopathy and more patients who started antihypertensive treatment $(62 \% v 14 \%, \mathrm{P}<0.001$; table 2$)$. We found no differences between groups for smoking status, height, or weight.

Significant baseline predictors for the development of persistent microalbuminuria were urinary albumin excretion rate, being male, mean arterial blood pressure, haemoglobin $A_{1 c}$ concentration, and height (table 3). No additional risk factors were included in the model after exclusion of baseline urinary albumin excretion rate or patients receiving antihypertensive treatment before onset of microalbuminuria $(n=6)$.

The 79 patients who progressed to persistent microalbuminuria were followed for a median of 7.5 years (range 0.1 to 15.8 years) after onset of microalbuminuria. During follow up, 28 of these patients (35.4\%) regressed to normoalbuminuria either transiently $(n=15)$ or permanently $(n=13$; table 4$)$. The cumulative incidence of regression over six years was $31 \%(20 \%$ to $42 \%$ ). Angiotensin converting enzyme inhibitors were taken by 11 of these patients. Three of the patients who regressed permanently to normoalbuminuria were treated with angiotensin converting enzyme inhibitors before and during regression, thus 10

Table 1 Baseline characteristics of 277 patients followed from onset of type 1 diabetes and progression to microalbuminuria. Values are means (SDs) unless stated otherwise

\begin{tabular}{lccccc} 
Characteristic & $\begin{array}{c}\text { No microalbuminuria } \\
(\mathbf{n}=\mathbf{1 9 8})\end{array}$ & $\begin{array}{c}\text { Microalbuminuria } \\
(\mathbf{n}=\mathbf{7 9})\end{array}$ & P value \\
\hline No $(\%)$ male & 108 & $(55)$ & 55 & $(70)$ & 0.02 \\
\hline Height $(\mathrm{cm})$ & 172 & $(13)$ & 168 & $(15)$ & 0.06 \\
\hline Weight $(\mathrm{kg})$ & 60.4 & $(13.5)$ & 59.2 & $(16.4)$ & 0.54 \\
\hline Age (years) & 27 & $(13)$ & 28 & $(17)$ & 0.91 \\
\hline $\begin{array}{l}\text { Systolic blood pressure } \\
\text { (mm Hg) }\end{array}$ & 122 & $(16)$ & 128 & $(19)$ & 0.007 \\
\hline $\begin{array}{l}\text { Diastolic blood } \\
\text { pressure (mm Hg) }\end{array}$ & 76 & $(10)$ & 80 & $(12)$ & 0.004 \\
\hline $\begin{array}{l}\text { Median (interquartile } \\
\text { range) urinary } \\
\text { albumin excretion } \\
\text { rate (mg/24 h) }\end{array}$ & 8 & $(5-13)$ & 11 & $(8-17)$ & 0.002 \\
\hline $\begin{array}{l}\text { Haemoglobin } \mathrm{A}_{1 \mathrm{c}} \\
\text { concentration }(\%)\end{array}$ & 9.7 & $(2.2)$ & 10.1 & $(1.8)$ & 0.16 \\
\hline $\begin{array}{l}\text { Serum cholesterol } \\
\text { concentration }(\mathrm{mM})\end{array}$ & 5.4 & $(1.5)$ & 5.6 & $(1.5)$ & 0.37 \\
\hline $\begin{array}{l}\text { Serum creatinine } \\
\text { concentration }(\mu \mathrm{M})\end{array}$ & 80 & $(16)$ & 77 & $(15)$ & 0.14 \\
\hline $\begin{array}{l}\text { Fasting plasma C } \\
\text { peptide level }(\mathrm{nM})\end{array}$ & 0.172 & $(0.093)$ & 0.175 & $(0.082)$ & 0.88 \\
\hline
\end{tabular}

Total cohort included 286 patients; nine patients were excluded from analyses. 
Table 2 Clinical data before development of microalbuminuria and during observation period in 277 patients followed from onset of type 1 diabetes. Values are numbers (percentages) unless stated otherwise

\begin{tabular}{|c|c|c|c|c|c|}
\hline \multirow{2}{*}{$\begin{array}{l}\text { Clinical details } \\
\text { Before } \\
\text { microalbuminuria }\end{array}$} & \multicolumn{2}{|c|}{$\begin{array}{l}\text { No microalbuminuria } \\
\qquad(\mathrm{n}=198)\end{array}$} & \multicolumn{2}{|c|}{$\begin{array}{l}\text { Microalbuminuria } \\
\quad(\mathrm{n}=79)\end{array}$} & \multirow[t]{2}{*}{$P$ value } \\
\hline & & & & & \\
\hline $\begin{array}{l}\text { Mean (SEM) height } \\
(\mathrm{cm})\end{array}$ & 174.9 & $(0.7)$ & 173.5 & $(1.0)$ & 0.27 \\
\hline $\begin{array}{l}\text { Mean (SEM) weight } \\
(\mathrm{kg})\end{array}$ & 75.4 & $(0.9)$ & 73.4 & (1.3) & 0.23 \\
\hline Smoking status: & & & & & 0.86 \\
\hline Smoker & 88 & (44) & 38 & (48) & \\
\hline Non-smoker & 67 & (34) & 25 & (32) & \\
\hline Former smoker & 43 & (22) & 16 & (20) & \\
\hline $\begin{array}{l}\text { Antihypertensive } \\
\text { treatment }\end{array}$ & 28 & (14) & 49 & (62) & $<0.001$ \\
\hline $\begin{array}{l}\text { No antihypertensive } \\
\text { treatment }\end{array}$ & 170 & (86) & 30 & (38) & $<0.001$ \\
\hline \multicolumn{6}{|l|}{ Retinopathy: } \\
\hline Absent & 80 & (40) & 4 & (5) & $<0.001$ \\
\hline Simplex & 115 & (58) & 61 & (77) & $<0.001$ \\
\hline Proliferative & 3 & (2) & 14 & (18) & $<0.001$ \\
\hline \multicolumn{6}{|l|}{ Follow up } \\
\hline $\begin{array}{l}\text { Mean (SEM) systolic } \\
\text { blood pressure (mm } \\
\mathrm{Hg})\end{array}$ & 127 & (0.9) & 129 & $(1.8)$ & 0.31 \\
\hline $\begin{array}{l}\text { Mean (SEM) diastolic } \\
\text { blood pressure (mm } \\
\mathrm{Hg})\end{array}$ & 78 & $(0.5)$ & 80 & $(0.9)$ & 0.10 \\
\hline $\begin{array}{l}\text { Geometric mean }(95 \% \\
\text { Cl) urinary albumin } \\
\text { excretion rate (mg/24 } \\
\text { h) }\end{array}$ & 8 & (8 to 9) & 14 & (12 to 16$)$ & $<0.001$ \\
\hline $\begin{array}{l}\text { Mean (SEM) } \\
\text { haemoglobin } \mathrm{A}_{1 \mathrm{c}} \\
\text { concentration (\%) }\end{array}$ & 8.3 & $(0.1)$ & 9.1 & $(0.1)$ & $<0.001$ \\
\hline $\begin{array}{l}\text { Mean (SEM) serum } \\
\text { cholesterol } \\
\text { concentration (mM) }\end{array}$ & 5.2 & $(0.1)$ & 5.5 & $(0.2)$ & 0.09 \\
\hline $\begin{array}{l}\text { Mean (SEM) serum } \\
\text { creatinine } \\
\text { concentration }(\mu \mathrm{M})\end{array}$ & 78 & $(0.7)$ & 76 & (1.6) & 0.26 \\
\hline $\begin{array}{l}\text { Insulin dose/body } \\
\text { weight (IU/kg) }\end{array}$ & 0.56 & $(0.01)$ & 0.56 & $(0.02)$ & 0.95 \\
\hline
\end{tabular}

patients underwent spontaneous permanent regression (13\%). Patients who became normoalbuminuric had a lower arterial blood pressure, urinary albumin excretion rate, and serum cholesterol concentration at onset of microalbuminuria than those with sustained microalbuminuria (table 4). The time from onset of diabetes to development of persistent microalbuminuria was 9.2 years in patients who became normoalbuminuric and 11.2 years in those with sustained microalbuminuria. Similarly, we found no difference in the yearly increase in urinary albumin excretion rate from onset of diabetes (baseline level $11 \mathrm{mg} / 24 \mathrm{~h}$ )

Table 3 Cox proportional hazard model of baseline risk factors for development of persistent microalbuminuria in 277 patients with type 1 diabetes followed for 18 years

\begin{tabular}{lcc} 
Variable & Relative risk $(\mathbf{9 5 \%} \mathbf{C l})$ & P value \\
\hline $\begin{array}{l}\text { Log }_{10} \text { urinary albumin excretion } \\
\text { rate (per } 10 \text {-fold increase) }\end{array}$ & $3.78(1.57$ to 9.13$)$ & 0.003 \\
\hline Sex (male $v$ female) & $2.41(1.43$ to 4.06$)$ & 0.001 \\
\hline $\begin{array}{l}\text { Mean arterial blood pressure (per } \\
10 \mathrm{~mm} \mathrm{Hg} \text { increase) }\end{array}$ & $1.38(1.20$ to 1.57$)$ & $<0.001$ \\
\hline $\begin{array}{l}\text { Haemoglobin } \mathrm{A}_{1 \mathrm{c}} \text { concentration } \\
\text { (per } 1 \% \text { increase) }\end{array}$ & $1.18(1.04$ to 1.32$)$ & $<0.01$ \\
\hline Height (per $1 \mathrm{~cm}$ increase) & $0.96(0.95$ to 0.98$)$ & $<0.001$ \\
\hline
\end{tabular}

Not included in final model were age at onset, weight, smoking status, serum cholesterol, and fasting plasma $\mathrm{C}$ peptide level.
Table 4 Characteristics of 79 patients with type 1 diabetes at onset of microalbuminuria: regression to normoalbuminuria compared with progression to persistent microalbuminuria or persistent macroalbuminuria. Values are means (SDs) unless stated otherwise

\begin{tabular}{|c|c|c|c|c|c|}
\hline \multirow{2}{*}{$\begin{array}{l}\text { Characteristic } \\
\text { No }(\%) \text { male }\end{array}$} & to norr & $\begin{array}{l}\text { 10albuminuria } \\
\text { l=28) }\end{array}$ & \multicolumn{2}{|c|}{$\begin{array}{c}\text { Persistent } \\
\text { microalbuminuria or } \\
\text { macroalbuminuria } \\
(n=51)\end{array}$} & \multirow{2}{*}{$\begin{array}{c}\text { P value } \\
0.44\end{array}$} \\
\hline & 21 & (75) & \multicolumn{2}{|c|}{$34 \quad(67)$} & \\
\hline No (\%) smokers & 10 & (36) & 28 & (55) & \\
\hline No (\%) non-smokers & 18 & (64) & 23 & (45) & 0.10 \\
\hline Height (cm) & 177 & (8) & 174 & (8) & 0.007 \\
\hline Weight (kg) & 74.3 & (13.3) & 74.1 & $(10.8)$ & 0.93 \\
\hline Age (years) & 33 & (17) & 41 & (16) & 0.056 \\
\hline $\begin{array}{l}\text { Duration of diabetes } \\
\text { (years) }\end{array}$ & 9.2 & (3.5) & 11.2 & (4.4) & 0.051 \\
\hline $\begin{array}{l}\text { Systolic blood pressure } \\
(\mathrm{mm} \mathrm{Hg})\end{array}$ & 127 & (17) & 140 & (17) & 0.003 \\
\hline $\begin{array}{l}\text { Diastolic blood pressure } \\
(\mathrm{mm} \mathrm{Hg})\end{array}$ & 79 & (10) & 84 & (8) & 0.03 \\
\hline $\begin{array}{l}\text { Median (interquartile } \\
\text { range) urinary } \\
\text { albumin excretion } \\
\text { rate }(\mathrm{mg} / 24 \mathrm{~h})\end{array}$ & 42 & $(35-63)$ & 59 & $(42-124)$ & 0.01 \\
\hline $\begin{array}{l}\text { Haemoglobin } A_{1 c} \\
\text { concentration (\%) }\end{array}$ & 9.2 & $(1.3)$ & 9.6 & (1.3) & 0.09 \\
\hline $\begin{array}{l}\text { Serum cholesterol } \\
\text { concentration } \\
(\mathrm{mmol} / \mathrm{l})\end{array}$ & 4.8 & $(1.0)$ & 5.4 & (1.4) & 0.03 \\
\hline
\end{tabular}

to development of microalbuminuria between patients who later reverted to normoalbuminuria and those with sustained microalbuminuria (19\%/year $v 21 \%$ /year). Eleven of the 79 patients (14\%) with microalbuminuria were not followed until 2000 (eight died, three were lost to follow up), but we ascertained data up to their last clinic visit. None of the patients who developed macroalbuminuria spontaneously regressed to microalbuminuria or normoalbuminuria.

\section{Discussion}

Around one third of patients newly diagnosed with type 1 diabetes develop persistent microalbuminuria within the first 20 years of diabetes. Baseline factors independently associated with progression to persistent microalbuminuria were urinary albumin excretion rate, being male, mean arterial blood pressure, haemoglobin $\mathrm{A}_{1 \mathrm{c}}$ concentration, and height. Over one third of the patients regressed from persistent microalbuminuria to transient or permanent normoalbuminuria. Only 13\% spontaneously regressed to permanent normoalbuminuria. We applied generally accepted guidelines to reduce the confounding influence of variability in urinary albumin excretion rate on classification to normoalbuminuria, microalbuminuria, or macroalbuminuria. ${ }^{13}$ To make the criteria even more stringent, we required a change of at least $30 \%$ in urinary albumin excretion rate. ${ }^{10} 11$

The use of baseline data rather than follow up data in observational studies can result in systematic and substantial underestimation of the strength of the association between baseline data and disease-so called regression dilution bias. ${ }^{14}$ Consequently our estimates of baseline predictors for development of persistent microalbuminuria may be regarded as conservative. Previous studies of risk factors for microalbuminuria in type 1 diabetes are based largely on prevalence cohorts with varying duration of diabetes at inclusion, and follow up for less than 10 years. $^{5-8}$ We performed a long term study of an inception cohort, which minimises bias due to inclusion, exclusion, and survival. 
Even when the urinary albumin excretion rate was within the normal range at baseline it was a strong predictor for development of persistent microalbuminuria. This finding confirms and extends data from previous prospective studies in patients with type 1 or type 2 diabetes. ${ }^{5}{ }^{815} 16$ An increased urinary albumin excretion rate even within the normal range probably reflects abnormal glomerular haemodynamics and permselectivity which may predispose to diabetic glomerulopathy. ${ }^{217}$ Differences in people's susceptibility to renal problems may be explained by differences in renal functional reserve capacity, as recently shown in patients with primary hypertension. ${ }^{18}$ Patients with reduced renal functional reserve capacity may be more prone to microalbuminuria when exposed to conditions such as hyperglycaemia or hypertension.

Men are at a higher risk of developing incipient or overt diabetic nephropathy. Whether this is due to genetic, hormonal, or environmental factors is unclear. Animal studies suggest that sex steroids may play a part in the pathogenesis of diabetic microangiopathy. ${ }^{19}$

Our study suggests that systemic increases in blood pressure, even at the onset of diabetes and within the normal range, have an important role in the development of persistent microalbuminuria, supporting the concept that glomerular hypertension is crucial in the initiation and progression of diabetic kidney disease. ${ }^{17}$ Previous studies have shown that a familial predisposition to hypertension increases the risk of developing diabetic nephropathy. ${ }^{20}{ }^{21}$. Observational studies have, however, produced conflicting results. ${ }^{5-8}$ These discrepancies may in part be due to differences in study design, methods of blood pressure measurement, the study population, duration of follow up, and other potential biases. Changes in systemic blood pressure may be small, which makes detection difficult unless validated, precise methods are used, such as ambulatory blood pressure measurements over 24 hours. ${ }^{22}$

Observational and intervention studies have shown that hyperglycaemia and glycaemic control play a major part in the development of microalbuminuria in patients with type 1 diabetes. ${ }^{5-8}{ }^{23}{ }^{24}$ We have shown that poor glycaemic control at onset of diabetes (determined by first assessment of haemoglobin $\mathrm{A}_{1 \mathrm{c}}$ concentration six months after the onset of type 1 diabetes) is an important predictor for the development of microalbuminuria. Efforts should therefore be made to normalise glycaemia when diabetes is first diagnosed. Our observations confirm the latest conclusions from the epidemiology of diabetes interventions and complications research study. ${ }^{25}$

Previously we showed a relation between short stature and development of overt diabetic nephropathy. ${ }^{26}$ It has been suggested that impaired intrauterine growth leads to a reduction in the number of nephrons, leading to systemic and glomerular hypertension in adulthood. ${ }^{27}$ Our current data support this hypothesis.

Regression from persistent microalbuminuria to normoalbuminuria occurred in over one third of our study population, with more than half of the patients relapsing to persistent microalbuminuria. Regression occurred spontaneously, as well as in those treated with angiotensin converting enzyme inhibitors. Only $13 \%$ underwent spontaneous permanent regression to normoalbuminuria without antihypertensive treatment. The patients undergoing regression had significantly lower arterial blood pressure, a lower urinary albumin excretion rate, and a lower serum cholesterol concentration at onset of microalbuminuria, and consequently they had a higher chance of reversal of renal lesions..$^{28}{ }^{29}$ Finally, misclassification may have played a part. A recent report showed that regression from persistent
What is already known on this topic

Risk factors for microalbuminuria and diabetic nephropathy are based on prevalence cohorts, often with short term follow up

Spontaneous regression of microalbuminuria to normoalbuminuria has been suggested to be common in patients with type 1 diabetes

\section{What this study adds}

Around one third of patients develop persistent microalbuminuria within 20 years of onset of type 1 diabetes

Urinary albumin excretion rate, arterial blood pressure, and glycaemic control at onset of diabetes predict progression from normoalbuminuria to microalbuminuria or macroalbuminuria

Spontaneous permanent regression from microalbuminuria to normoalbuminuria is rare, suggesting that, in most cases, microalbuminuria represents relentless progressive nephropathy

microalbuminuria to normoalbuminuria is common in patients with type 1 diabetes. ${ }^{30}$ Since angiotensin converting enzyme inhibitors were not associated with regression to microalbuminuria, the data suggest spontaneous normalisation. The difference in the proportion of patients who regressed in the two studies may be partly explained by differences in design. One study evaluated a prevalence cohort, introducing the possibility of inclusion, exclusion, and survival bias.

We found a lower cumulative incidence of diabetic nephropathy than with previous prevalence cohorts from the same institution. ${ }^{9}$ This may be explained by improved glycaemic control, lower blood pressure, and fewer smokers. ${ }^{9}$

We thank Birgitte V Hansen, Ulla Smidt, Tina Juhl, Lotte Pietraszek, and Inge-Lise Rossing for expert technical assistance.

Contributors: $\mathrm{PH}$ assessed and evaluated the patients during the last five years of follow up, planned and carried out the data analyses, and drafted the paper. LT, PR, BRJ, IT, MG, and CB reviewed the paper. LT assessed and evaluated the patients during the last 10 years of follow up. PR supervised the data analyses. BRJ participated in data collection and supervised data collection and laboratory analyses for the last 10 years. IT participated in data collection and supervised data collection and laboratory analyses until 1994. MG participated in data collection and the care and the follow up of the patients. CB designed the study, supervised all phases of the study including patient treatment and evaluation until 1994. H-HP supervised all phases of the study for the last 10 years, including patient treatment and evaluation, and supervised the writing of the paper. PH and H-HP will act as guarantors for the paper.

Funding: This study was funded by the Danish Diabetes Association, the Paul and Erna Sehested Hansen Foundation, the Aase and Ejnar Danielsen Foundation, and the Per S Henriksen Foundation.

Competing interests: CB holds stocks in Novo Nordisk, which makes products related to the treatment of diabetes, and is a paid consultant by the same company for clinical quality assurance and quality improvement in diabetes care.

Ethical approval: This study was approved by the local ethics committee in Copenhagen.

1 Parving H-H, Oxenbøll B, Svendsen PA, Christiansen JS, Andersen AR. Early detection of patients at risk of developing diabetic nephropathy Acta Endocrinol 1982;100:550-5. Parving H-H, Østerby R, Ritz E. Diabetic nephropathy. In Brenner BM, ed. The kidney. Parving H-H, Østerby R, Ritz E. Diabetic nephr.
Philadelphia: WB Saunders, 2000:1731-73.

3 Viberti GC, Hill RD, Jarrett RJ, Argyropoulos A, Mahmud U, Keen H. Microalbuminuria as a predictor of clinical nephropathy in insulin-dependent diabetes mellitus. Lancet 1982;i:1430-2. 
4 Bangstad H-J, Østerby R, Dahl-Jørgensen K, Berg K, Hartmann A, Nyberg G, et al. Early glomerulopathy is present in young, type 1 (insulin-dependent) diabetic patients with microalbuminuria. Diabetologia 1993;36:523-9.

5 Mathiesen ER, Rønn B, Jensen T, Storm B, Deckert T. Relationship between blood pressure and urinary albumin excretion in development of microalbuminuria. Diabetes 1990;39:245-9.

6 Coonrod BA, Ellis D, Becker DJ, Bunker CH, Kelsey SF, Lloyd CE, et al. Predictors of microalbuminuria in individuals with IDDM. Pittsburgh epidemiology of diabetes complications study Diabetes Care 1993;16:1376-83.

7 The Microalbuminuria Collaborative Study Group. Predictors of the development of microalbuminuria in patients with type 1 diabetes mellitus: a seven-year prospective study. Diabetic Med 1999;16:918-25.

8 Rossing P, Hougaard P, Parving H-H. Risk factors for development of incipient and overt diabetic nephropathy in type 1 diabetic patients. Diabetes Care 2002;25:859-64.

9 Hovind P, Tarnow L, Rossing K, Rossing P, Eising S, Larsen N, et al. Decreasing incidence of severe diabetic microangiopathy in type 1 diabetes. Diabetes Care 2003:26:1258-64.

10 Viberti GC, Mogensen CE, Groop L, Pauls JF, the European Microalbuminuria Captopril Study Group. Effect of Captopril on progression to clinical proteinuria in patient with insulin-dependent diabetes mellitus and microalbuminuria. JAMA 1994:271:275-9.

11 Parving H-H, Lehnert H, Bröchner-Mortensen J, Gomis R, Andersen S, Arner P. The Effect of Irbesartan on the development of diabetic nephropathy in patients with type 2 diabetes. $N$ Engl J Med 2001;345:870-8.

12 Faber OK, Binder C. B-cell function and blood glucose control in insulin dependen diabetics within the first month of insulin treatment. Diabetologia 1977;13:263-8.

13 Mogensen CE, Keane WF, Bennett PH, Jerums G, Parving H-H, Passa P, et al. Prevention of diabetic renal disease with special reference to microalbuminuria. Lancet 1995:346:1080-4

14 MacMahon S, Peto R, Curtler J, Collins R, Sorlie P, Neaton J, et al. Blood pressure, stroke and coronary heart disease, part 1: prolonged differences in blood pressure: prospective observational studies corrected for the regression dilution bias. Lance 1990;335:765-74

15 The Diabetes Control and Complications Trial Research Group. Effect of intensive therapy on the development and progression of diabetic nephropathy in the diabetes control and complications trial. Kidney. Int 1995;47:1703-20.

16 Gall M-A, Hougaard P, Borch-Johnsen K, Parving H-H. Risk factors for development of incipient and overt diabetic nephropathy in patients with non-insulin dependent diabetes mellitus: prospective, observational study. BMJ 1997;314:783-8.

17 Hostetter TH, Rennke HG, Brenner BM. The case for intrarenal hypertension in the nitiation and progression of diabetic and other glomerulopathies. Am J Med 1982;72:375-80.

18 Keller G, Zimmer G, Mall G, Ritz E, Amann K. Nephron number in patients with primary hypertension. N EnglJ Med 2003;348:101-8.

19 Williamson JR, Rowold E, Chang K, Marvel J, Tomlinson M, Sherman WR, et al. Sex steroid dependency of diabetes-induced changes in polyol metabolism, vascular permeability, and collagen cross-linking. Diabetes 1986;35:20-7.

20 Viberti GC, Keen H, Wiseman MJ. Raised arterial pressure in parents of proteinuric insulin-dependent diabetics. BMJ 1987;295:515-7.

21 Fagerudd JA, Tarnow L, Jacobsen P, Stenman S, Nielsen FS, Pettersson-Fernholm KJ, et al. Predisposition to essential hypertension and development of diabetic nephropathy in IDDM patients. Diabetes 1998;47:439-44
22 Lurbe E, Redon J, Kesani A, Pascual JM, Tacons J, Alvarez V, et al. Increase in nocturnal blood pressure and progression to microalbuminuria in type 1 diabetes. $N$ Engl J Med 2002:347:797-805

23 The Diabetes Control and Complications Trial Research Group. The effect of intensive treatment of diabetes on the development and progression of long-term complications in insulin-dependent diabetes mellitus. N Engl J Med 1993;329:977-86.

24 Wang PH, Lau J, Chalmers TC. Meta-analysis of effects of intensive blood-glucose control on late complications of type I diabetes. Lancet 1993;341:1306-9.

25 The writing team for the Diabetes Control and Complications Trial/Epidemiology of Diabetes Interventions and Complications Research Group. Sustained effect of intensive treatment of type 1 diabetes mellitus on development and progression of dibetc sive treat of nephropathy: the Epidemiology of Diabetes Interventions and Complications (EDIC)

26 Rossing P, Tarnow L, Nielsen FS, Boelskifte S, Brenner BM, Parving H-H. Short stature and diabetic nephropathy. BMJ 1995;310:296-7.

27 Brenner BM, Chertow GM. Congenital oligonephropathy and the etiology of adult hypertension and progressive renal injury. Am J Kidney Diseases 1994;23:171-5.

28 Fioretto P, Steffes MW, Sutherland DER, Goetz FC, Mauer M. Reversal of lesions of diabetic nephropathy after pancreas transplantation. N Engl J Med 1998;339:69-75.

29 Cordonnier DJ, Pinel N, Barro C, Maynard C, Zaoui P, Halimi S, et al. Expansion of cortical interstitium is limited by converting enzyme inhibition in type 2 diabetic patients with glomerulosclerosis. JAm Soc Nephrol 1999;10:1253-63.

30 Perkins BA, Ficociello LH, Silva KH, Finkelstein DM, Warram JH, Krolewski AS Regression of microalbuminuria in type 1 diabetes. N Engl J Med 2003;348:2285-93.

(Accepted 5 March 2004)

doi $10.1136 / \mathrm{bmj} .38070 .450891 . \mathrm{FE}$

Steno Diabetes Center, Niels Steensens Vej 2, DK-2820 Gentofte, Denmark Peter Hovind medical doctor

Lise Tarnow medical doctor

Peter Ross

Berit Ruud Jensen laboratory technician

Malene Graae consultant nurse

Inge Torp laboratory technician

Christian Binder chief physician

Hans-Henrik Parving professor

Correspondence to: P Hovind phovind@dadlnet.dk

\section{Amendment}

This is Version 2 of the paper. In this version the address for Hans-Henrik Parving has been changed. It is now given as the Steno Diabetes Center [in the previous version it was the University of Aarhus]. 